\title{
Gender Differences Among Veterans Deployed in Support of the Wars in Afghanistan and Iraq
}

\author{
Amy E. Street, $P h D^{1,2}$, Jaimie L. Gradus, DSc, $M P H^{1,2,3}$, Hannah L. Giasson, BA', \\ Dawne Vogt, $P h D^{1,2}$, and Patricia A. Resick, $P h D^{1,2}$ \\ 1. National Center for PTSD, VA Boston Healthcare System, Boston, MA, USA; ${ }^{2}$ Department of Psychiatry, Boston University School of Medicine, \\ Boston, MA, USA; ${ }^{3}$ Department of Epidemiology, Boston University School of Public Health, Boston, MA, USA.
}

BACKGROUND: The changing scope of women's roles in combat operations has led to growing interest in women's deployment experiences and post-deployment adjustment.

OBJECTIVES: To quantify the gender-specific frequency of deployment stressors, including sexual and nonsexual harassment, lack of social support and combat exposure. To quantify gender-specific post-deployment mental health conditions and associations between deployment stressors and posttraumatic stress disorder (PTSD), to inform the care of Veterans returning from the current conflicts.

DESIGN: National mail survey of OEF/OIF Veterans randomly sampled within gender, with women oversampled.

SETTING: The community.

PARTICIPANTS: In total, 1,207 female and 1,137 male Veterans from a roster of all Operation Enduring Freedom/Operation Iraqi Freedom (OEF/OIF) Veterans. Response rate was $48.6 \%$.

MAIN MEASURES: Deployment stressors (including combat and harassment stress), PTSD, depression, anxiety and alcohol use, all measured via self-report.

KEY RESULTS: Women were more likely to report sexual harassment $(\mathrm{OR}=8.7,95 \% \mathrm{CI}: 6.9,11)$ but less likely to report combat $(\mathrm{OR}=0.62,95 \% \mathrm{CI}$ : 0.50, 0.76). Women and men were equally likely to report symptoms consistent with probable PTSD (OR $=0.87,95 \%$ CI: $0.70,1.1)$ and symptomatic anxiety (OR $=1.1,95 \% \mathrm{CI}$ : $0.86,1.3)$. Women were more likely to report probable depression (OR=1.3, $95 \% \mathrm{CI}: 1.1,1.6)$ and less likely to report problematic alcohol use $(\mathrm{OR}=0.59,95 \% \mathrm{CI}$ : $0.47,0.72$ ). With a five-point change in harassment stress, adjusted odds ratios for PTSD were 1.36 (95\% CI: $1.23,1.52)$ for women and 1.38 (95\% CI: 1.19, 1.61) for men. The analogous associations between combat stress and PTSD were 1.31 (95\% CI: 1.24, 1.39) and 1.31 (95 \% CI: 1.26, 1.36), respectively.

CONCLUSIONS: Although there are important gender differences in deployment stressors-including women's increased risk of interpersonal stressors-and post-deployment adjustment, there are also significant similarities. The post-deployment adjustment of our nation's growing population of female Veterans seems comparable to that of our nation's male Veterans.

KEY WORDS: veteran; women; sexual harassment; PTSD.
J Gen Intern Med 28(Suppl 2):S556-62

DOI: $10.1007 / \mathrm{s} 11606-013-2333-4$

(c) Society of General Internal Medicine 2013

F emale service members have long served with distinction in the U.S. military, and their contributions have grown substantially in the wars in Afghanistan (Operation Enduring Freedom; OEF) and Iraq (Operation Iraqi Freedom; OIF), both in terms of the number of women deployed $^{1}$ and the wider range of potentially dangerous combat and combat support positions in which they are serving. ${ }^{2}$ This new era of women's involvement in war-zone deployments raises important questions that must be answered to inform the mental health treatment needs of returning women Veterans.

Experiences of sexual harassment and assault during military service are a critical issue when considering the traumatic stress burden of female service members. While a wealth of data have documented a high frequency of these experiences in military samples, ${ }^{3-8}$ a limited number of investigations have examined unwanted sexual experiences specifically among OEF/OIF Veterans. Unfortunately, these experiences are not the only interpersonal stressor confronting female service members. Military women are more likely than their male counterparts to experience non-sexual gender-based harassment ${ }^{3,4}$ and a lack of social support from military peers and leadership., ${ }^{3,9}$ These experiences likely contribute to the overall deployment stressor burden among female service members. To date, no investigations have examined gender differences in non-sexual harassment or deployment social support among this cohort.

A more substantial body of research is emerging on exposure to combat trauma among female service members who served in OEF/OIF. ${ }^{10,11}$ Although Department of Defense policy prohibits women from serving in many direct combat roles, ${ }^{12}$ the roles in which women are serving place them at risk for traumatic combat-related events. ${ }^{13}$ More work in this area is needed, as existing studies have not assessed a wide range of traumatic combat experiences, or are limited in generalizability because of unique sample 
characteristics (e.g., single military branch, limited deployment time period).

A natural extension of the research examining the occurrence of potentially traumatic deployment experiences is the investigation of post-deployment mental health conditions. Among nondeployed, peacetime female Veteran samples, there are associations between unwanted sexual experiences and mental health conditions (e.g., posttraumatic stress disorder [PTSD], depression, anxiety, substance abuse). ${ }^{5,6}$ In studies of Veterans of the 1990-1991 Gulf War, sexual trauma was a strong predictor of postdeployment mental health. ${ }^{3,7}$ With a single exception, ${ }^{11}$ investigations of sexual trauma among OEF/OIF troops have been limited to Veterans Affairs (VA) healthcare users based on administrative data sources, ${ }^{14-16}$ or smaller, female-only samples with limited generalizability and no ability for gender comparisons, ${ }^{17,18}$ making it difficult to draw definitive conclusions. The one study that examined gender differences in PTSD symptoms following military sexual trauma in a large sample of active duty soldiers from the OEF/OIF cohort found no differences. ${ }^{11}$

Studies of gender differences in PTSD symptoms following combat exposure in the OEF/OIF cohort have been mixed. Although data from Army administrative databases using limited measurement suggests increased vulnerability among female soldiers, ${ }^{19,20}$ several other studies have found no gender differences in post-deployment mental health consequences when accounting for levels of combat exposure. ${ }^{10,13,21}$

The aims of the current investigation are to examine gender-specific (1) frequency of deployment stressors including sexual harassment, general harassment, unit support, combat and other war-related trauma; (2) frequency of post-deployment mental health conditions, including PTSD, depression, anxiety and clinically significant alcohol use; (3) associations between deployment stressors and PTSD. Based on existing literature, ${ }^{2,10,16}$ we expected women would be more likely to report interpersonal stressors, while men would be more likely to report combat-related stressors, particularly when stressors were stringently defined. While the existing evidence base is mixed, the strongest data suggest that male and female Veterans would report comparable levels of PTSD symptoms and comparable associations between stressors and PTSD. We anticipated gender differences in other postdeployment mental health conditions consistent with the general population (i.e., women more likely to report depression, men more likely to report alcohol use). ${ }^{22}$

\section{METHODS}

\section{Participants}

In June, 2009, potential participants were randomly selected, within gender, from the DoD Manpower Data
Center's roster of OEF/OIF Veterans separated from active duty service held by the Department of Veterans Affairs Environmental Epidemiology Service. Female Veterans were oversampled, with gender serving as the only stratification variable. In the initial sampling of 6,000, 940 potential participants did not have a valid address and no address information could be obtained via location searches. Of the remaining 5,060 potential participants, 123 were ineligible (i.e., never deployed in support of OEF/OIF; currently deployed; deceased), 213 declined participation and four were removed, as administrative data used for weighted analyses was unavailable. The final sample consisted of 2,344 participants (1,137 male and 1,207 female Veterans), representing a response rate of $48.6 \%$ after correcting for estimated ineligibility among nonresponders. Table 1 displays participants' self-reported demographic and military characteristics.

To identify the extent to which participants represent the full sampling frame, we compared survey responders to nonresponders on demographic and military characteristics drawn from administrative data. Differences were small and not meaningful with regard to gender $(\mathrm{phi}=-0.021)$, race (Cramer's $V=0.069$ ), military rank (officer vs. enlisted; Cramer's $V=0.146$ ), military branch (Cramer's $V=0.055$ ), and duty status (active duty vs. Reserves/Guard; Cramer's $V=0.093$ ). There was a small-to-medium effect for age difference (Cohen's $\mathrm{d}=-0.445$ ), with responders 4 years older, on average, than non-responders.

\section{Procedure}

Prior to initiating data collection, approvals were obtained from the Institutional Review Board of VA Boston HCS and the Office of Management and Budget. As recommended by Dillman, ${ }^{23}$ a multi-stage mailing procedure was used, including: (1) an introductory letter alerting potential participants to the survey; (2) a paper and pencil survey, a postage-paid return envelope and $\$ 5$ cash incentive 1 week later; (3) reminder/thank you postcard 1 week later; (4) a second survey to non-responders 1 week later; (5) a third survey to non-responders 3 weeks later via priority mail. A fact sheet detailing the elements of informed consent was included with each survey. Completion of the survey required approximately $20 \mathrm{~min}$, on average.

\section{Measures}

Scales from the Deployment Risk and Resiliency Inventory (DRRI) ${ }^{24}$ measured a range of war-zone stressors. The DRRI has strong reliability and validity for factors contributing to Veterans' post-deployment wellbeing. ${ }^{25,26}$ Sexual Harassment Scale: Seven items 
Table 1. Unweighted Sample Demographic and Military Service Characteristics, by Gender

\begin{tabular}{|c|c|c|}
\hline & $\begin{array}{l}\text { Women } \\
(n=1,207)\end{array}$ & $\begin{array}{l}\text { Men } \\
(n=1,137)\end{array}$ \\
\hline Age $M(S D)^{a}$ & $34(8.8)$ & $37(10.1)$ \\
\hline \multicolumn{3}{|l|}{$\operatorname{Race}^{\mathrm{a}}$} \\
\hline White & $70.9 \%$ & $83.8 \%$ \\
\hline African American & $20.8 \%$ & $8.8 \%$ \\
\hline Other & $8.3 \%$ & $7.4 \%$ \\
\hline Number of OEF/OIF Deployments & $1.3(0.65)$ & $1.4(0.76)$ \\
\hline \multicolumn{3}{|l|}{$\mathrm{M}(\mathrm{SD})^{\mathrm{a}}$} \\
\hline \multicolumn{3}{|l|}{ Total Months Deployed to OEF/OIF } \\
\hline $\mathrm{M}(\mathrm{SD})^{\mathrm{a}}$ & $11(7.4)$ & $12(8.5)$ \\
\hline \multicolumn{3}{|l|}{ Location of Deployment: } \\
\hline$\%$ deployed to Iraq ${ }^{\mathrm{a}}$ & $57.4 \%$ & $68.6 \%$ \\
\hline$\%$ deployed to Afghanistan & $12.3 \%$ & $14.7 \%$ \\
\hline$\%$ deployed to other locations ${ }^{\mathrm{a}}$ & $37.1 \%$ & $28.4 \%$ \\
\hline \multicolumn{3}{|l|}{ Military Occupation Specialty: } \\
\hline$\%$ served Combat-Arms $^{\mathrm{a}}$ & $6.0 \%$ & $33.2 \%$ \\
\hline$\%$ served Combat-Support $^{\mathrm{a}}$ & $50.7 \%$ & $44.7 \%$ \\
\hline$\%$ served Service-Support ${ }^{\mathrm{a}}$ & $40.9 \%$ & $20.8 \%$ \\
\hline \multicolumn{3}{|l|}{ Branch of Military Service $^{a}$} \\
\hline Marines & $4.3 \%$ & $14.2 \%$ \\
\hline Army & $55.3 \%$ & $51.9 \%$ \\
\hline Navy & $15.7 \%$ & $12.3 \%$ \\
\hline Air Force & $24.0 \%$ & $21.0 \%$ \\
\hline Coast Guard & $0.3 \%$ & $0.1 \%$ \\
\hline Multiple Branches & $0.3 \%$ & $0.5 \%$ \\
\hline \multicolumn{3}{|l|}{ Military Service Component } \\
\hline Reserves/Guard & $48.1 \%$ & $50.8 \%$ \\
\hline Active Duty & $50.5 \%$ & $47.3 \%$ \\
\hline Both Reserves/Guard and Active Duty & $1.4 \%$ & $1.9 \%$ \\
\hline
\end{tabular}

${ }^{a}$ Denotes a significant difference between genders, $p<0.01$

assessing unwanted sexual experiences, including sexual harassment and assault. General Harassment Scale: Seven items assessing harassment on the basis of one's gender, ethnicity or other social status characteristic. Unit Support Scale: 12 items assessing perception of social support from unit members and leadership. Combat Experiences Scale: 15 items assessing combat experiences (e.g., directing fire at the enemy, receiving hostile incoming fire). Aftermath of Battle Scale: 15 items assessing stressful post-battle experiences, (e.g., taking care of wounded, seeing dead bodies). Prior Stressors: We selected eight potentially traumatic premilitary experiences (e.g., witnessed someone being assaulted or violently killed; unwanted sexual activity) from the 15 -item prior stressors scale, examined as a potentially confounding variable. All scales use a Likert response format. Internal consistency estimates for these scales ranged from 0.84 to 0.94 .

Probable PTSD was assessed using the Posttraumatic Stress Disorder Checklist-Military (PCL-M), ${ }^{27}$ a measure of how bothered respondents were by the 17 DSM-IV PTSD symptoms over the past month, keyed to "stressful deployment experiences," and using a Likert scale response of 1 ("not at all") to 5 ("extremely"). Consistent with other large studies examining postdeployment mental health, ${ }^{28,29}$ we used a cut-off of 50 to develop a dichotomous probable PTSD/no PTSD variable. ${ }^{30}$ Internal consistency was 0.97 .
Probable depression was measured using the ten-item Boston version of the Center for Epidemiologic Studies Depression Scale (CES-D). ${ }^{31}$ Participants rated how often they experienced depression-related symptoms within the past week using a Likert response scale from 1 ("None of the time or less than 1 day") to 4 ("5-7 days"). ${ }^{32}$ We used a cut-off of 10 to create probable depression/no depression groups. ${ }^{32}$ Internal consistency was 0.90 .

Anxiety symptoms were measured using the Anxiety Subscale of the Depression Anxiety Stress Scales (DASS). ${ }^{33,34}$ Participants indicated the degree to which 14 statements about autonomic arousal, skeletal musculature effects, situational anxiety, and subjective experience of anxious affect applied to them over the past week, using a response scale ranging from 1 ("Did not apply to me at all") to 4 ("Applied to me very much, or most of the time"). We used a cut-off of 7 to create normal anxiety/symptomatic anxiety groups. ${ }^{34}$ Internal consistency was 0.93 .

Clinically significant alcohol use was measured using The CAGE Questionnaire. ${ }^{35}$ Participants selected "Yes" or "No" to four questions about their drinking behavior (e.g., "Have you felt you ought to cut down on your drinking?"). We used a cut-off of 2 to create clinically significant alcohol use/no clinically significant alcohol use groups. ${ }^{36}$ Internal consistency was 0.74 .

\section{Statistical Analysis}

To enhance the representativeness of our results, weights were applied to adjust for nonresponse bias following procedures recommended by Groves et al. ${ }^{37}$ Specifically, we conducted a logistic regression using all potential participants with "returned survey" as the dependent variable and age, race, branch, component and rank as independent variables (from administrative data sources). This analysis estimated the probability of returning the survey for each potential participant, the reciprocal of which was the nonresponse weight. The application of nonresponse weights contributed to the computation of unbiased estimates and correct standard errors. STATA software and survey (svy) commands are designed to handle the special requirements of complex survey data and were used for all weighted analyses.

In the absence of objective, validated cut points, we examined the gender-stratified frequencies of deployment stressors two ways: the proportion of participants who reported experiencing any level of stressor exposure (liberal definition), and the proportion of participants who reported experiencing a stressor at a level that exceeded one third of the possible total of that deployment stressor scale (conservative definition). We conducted logistic regression analyses to examine the 
associations between gender and each deployment stressor. Similarly, we identified gender-specific frequencies of post-deployment mental health conditions and used logistic regression to examine associations between each condition and gender. Men were the reference group for all analyses.

We also conducted a series of gender-stratified logistic regressions to examine adjusted associations between deployment stressors identified in previous research as the most likely correlates of post-deployment mental health issues (i.e., harassment stress, combat stress) and probable PTSD. To identify the strongest confounding variables to be included in the final regressions, we used an model-fitting procedure ${ }^{38}$ beginning with a set of conceptually relevant variables from the literature, including age, race (white vs. nonwhite), number of prior (pre-military) stressors, place of deployment (Iraq or Afghanistan vs. other), number of deployments (one vs. multiple), number of months deployed, unit type (active duty vs. Reserves/Guard), rank (enlisted vs. officer), time since deployment (months) and deployment stressor variables. Conceptually similar deployment stressor variables were combined to create predictor variables (combined sexual and general harassment [Cronbach's alpha $=0.91]$, combined combat exposure and aftermath of battle [Cronbach's alpha $=0.96]$ ). As these predictor variables are continuous, the estimated adjusted odds ratios (aOR) represent the change in probable PTSD odds for 1-point change in deployment stress exposure and as such are expected to be modest in strength. Accordingly, we also computed the probable PTSD odds for a 5-point change in predictors of interest. Because the stressor exposure scales assess the occurrence and frequency of deployment stressors, a 5-point change reflects having a greater range of experiences or having one particular experience more times.

\section{RESULTS}

Table 2 displays the gender-specific frequencies of deployment stressors, including the proportion of participants who experienced any level of stressor exposure, using liberal and conservative definitions, and odds ratios (OR) and $95 \%$ confidence intervals (CI) demonstrating the gender and deployment stressor association. For any level of stressor exposure, female Veterans were significantly more likely to report sexual harassment, general harassment and lack of unit support, but significantly less likely to report combat and aftermath of battle. The analyses examining the conservative definition of stressor exposure followed the same pattern with generally stronger effects.

Table 3 displays the gender-specific frequencies of probable post-deployment mental health conditions and the ORs and $95 \%$ CIs comparing proportions. Female and male Veterans were equally likely to report symptoms of probable PTSD and symptomatic anxiety. However, female Veterans were more likely to report symptoms of probable depression and less likely to report symptoms of clinically significant alcohol use.

Table 4 displays the results of the gender-stratified analyses examining adjusted associations between deployment stressors and probable PTSD. The aORs associated with a 5-point change in harassment stress and probable PTSD were similar in women (1.36) and men (1.38). The aORs for combat stress and probable

Table 2. Gender Differences in Deployment Stressors

\begin{tabular}{|c|c|c|c|c|c|c|}
\hline & \multicolumn{3}{|c|}{ Any level of stressor exposure ${ }^{a}$} & \multicolumn{3}{|c|}{ Conservatively defined stressor exposure $^{a}$} \\
\hline & $\begin{array}{l}\text { Females } \\
(n=1,207)\end{array}$ & $\begin{array}{l}\text { Males } \\
(n=1,137)\end{array}$ & $\begin{array}{l}\text { OR } \\
(95 \% \text { CI })\end{array}$ & $\begin{array}{l}\text { Females } \\
(n=1,207)\end{array}$ & $\begin{array}{l}\text { Males } \\
(n=1,137)\end{array}$ & $\begin{array}{l}\text { OR } \\
(95 \% \text { CI })\end{array}$ \\
\hline $\begin{array}{l}\text { Sexual } \\
\text { Harassment }\end{array}$ & $51.2 \%{ }^{\mathrm{b}}$ & $11.1 \%$ & $8.7(6.9,11)$ & $9.5 \%$ & $0.1 \%$ & $-^{\mathrm{c}}$ \\
\hline $\begin{array}{l}\text { General } \\
\text { Harassment }\end{array}$ & $77.6 \%{ }^{b}$ & $71.5 \%$ & $1.4(1.1,1.7)$ & $35.8 \%{ }^{\mathrm{b}}$ & $22.3 \%$ & $1.9(1.6,2.4)$ \\
\hline $\begin{array}{l}\text { (Lack of) } \\
\text { Unit Support }\end{array}$ & $60.1 \%^{\mathrm{b}}$ & $52.6 \%$ & $1.4(1.1,1.6)$ & $18.3 \%{ }^{\mathrm{b}}$ & $8.2 \%$ & $2.5(1.9,3.3)$ \\
\hline $\begin{array}{l}\text { Combat } \\
\text { Experiences }\end{array}$ & $73.4 \%$ & $81.7 \%{ }^{\mathrm{b}}$ & $0.62(0.50,0.76)$ & $8.8 \%$ & $29.1 \%{ }^{\mathrm{b}}$ & $0.23(0.18,0.30)$ \\
\hline $\begin{array}{l}\text { Aftermath of } \\
\text { Battle }\end{array}$ & $73.0 \%$ & $78.9 \%{ }^{b}$ & $0.73(0.59,0.89)$ & $15.4 \%$ & $32.2 \%{ }^{\mathrm{b}}$ & $0.38(0.31,0.47)$ \\
\hline
\end{tabular}

${ }^{a}$ Sexual Harassment, cut point for any level of stressor exposure=7, cut-point for conservatively defined stressor exposure=14; General Harassment, cut point for any level of stressor exposure = 7, cut-point for conservatively defined stressor exposure =14; Unit Support, cut point for any level of stressor exposure $=12$, cut-point for conservatively defined stressor exposure=28; Combat Experiences, cut point for any level of stressor exposure $=15$, cut-point for conservatively defined stressor exposure $=30$; Aftermath of Battle, cut point for any level of stressor exposure $=$ 15, cut-point for conservatively defined stressor exposure=30; In all cases, the cut point for any level of stressor exposure is equal to the lowest possible score on the scale

${ }^{b}$ Denotes group that is significantly more likely to report experience

${ }^{c}$ Could not be estimated due to the small number of males categorized as having a sexual harassment experience within this conservative definition $(n=1)$ 
Table 3. Gender Differences in Symptoms Consistent with Mental Health Conditions

\begin{tabular}{llll}
\hline \hline & $\begin{array}{l}\text { Women } \\
(\boldsymbol{n}=\mathbf{1 , 2 0 7})\end{array}$ & $\begin{array}{l}\text { Men } \\
(\boldsymbol{n}=\mathbf{1 , 1 3 7 )}\end{array}$ & $\begin{array}{l}\text { OR } \\
(\mathbf{9 5} \% \mathbf{C I})\end{array}$ \\
\hline Probable PTSD & $21.0 \%$ & $23.4 \%$ & $0.87(0.70,1.1)$ \\
Probable Depression & $38.3 \%{ }^{\mathrm{a}}$ & $31.8 \%$ & $1.3(1.1,1.6)$ \\
Symptomatic Anxiety & $24.1 \%$ & $23.1 \%$ & $1.1(0.86,1.3)$ \\
Clinically Significant & $17.7 \%$ & $26.9 \%{ }^{\mathrm{a}}$ & $0.59(0.47,0.72)$ \\
Alcohol Use & & & \\
\hline
\end{tabular}

${ }^{a}$ Denotes group that is significantly more likely to report experience

PTSD were also comparable in women (1.31) and men (1.31).

\section{DISCUSSION}

This study represents one of the first and largest efforts to compare experiences of female and male OEF/OIF Veterans on deployment stressors including sexual harassment, general harassment, social support, combat and other war-related trauma. It also represents the first effort to examine these issues in a sample obtained through random sampling of a broad population of separated OEF/OIF service members, including representation from all military branches.

As expected, our results indicate that women were more likely to experience sexual harassment than men, with about half of women reporting unwanted sexual experiences during deployment. We conceptualized this stressor on a continuum including both harassment (e.g., "made crude and offensive sexual remarks directed at me") and assault (e.g., "made unwanted attempts to stroke or fondle me"). However, examination of the specific experiences women reported provides important contextual information: $50 \%$ of our female sample reported experiencing non-assault sexual harassment, while $25 \%$ reported experiencing sexual assault (comparable numbers for males were $11 \%$ and $1 \%$, respectively). These data emphasize the importance of sexual trauma as a deployment stressor for female Veterans,

Table 4. Associations Between Deployment Stress Variables and Probable PTSD, by Gender

\begin{tabular}{lll}
\hline \hline & $\begin{array}{l}\text { Women } \\
\text { aOR (95 \% CI) }\end{array}$ & $\begin{array}{l}\text { Men } \\
\text { aOR }(95 \% \text { CI) }\end{array}$ \\
\hline $\begin{array}{l}\text { 1-point Change in } \\
\text { Harassment Stress }\end{array}$ & $1.06(1.04,1.09)^{\mathrm{a}}$ & $1.07(1.04,1.10)^{\mathrm{b}}$ \\
$\begin{array}{l}\text { 5-point Change in } \\
\text { Harassment Stress }\end{array}$ & $1.36(1.23,1.52)^{\mathrm{a}}$ & $1.38(1.19,1.61)^{\mathrm{b}}$ \\
$\begin{array}{l}\text { 1-point Change in } \\
\text { Combat Stress }\end{array}$ & $1.06(1.04,1.07)^{\mathrm{c}}$ & $1.06(1.05,1.06)^{\mathrm{d}}$ \\
$\begin{array}{l}\text { 5-point Change in } \\
\text { Combat Stress }\end{array}$ & $1.31(1.24,1.39)^{\mathrm{c}}$ & $1.31(1.26,1.36)^{\mathrm{d}}$ \\
\hline
\end{tabular}

${ }^{a}$ Model adjusted for unit support, combined combat stress

${ }^{b}$ Model adjusted for rank, combined combat stress

${ }^{c}$ Model adjusted for combined harassment stress

${ }^{d}$ No confounders identified, aOR identical to OR and suggests investigations that do not include measurement of this construct are underestimating the stressor burden for female military personnel.

In the first large-scale examination of these issues, women were also more likely than men to be exposed to other interpersonal stressors (e.g., general harassment, lack of support). These findings have important implications for the post-deployment adjustment of women, as cohesive relationships among military personnel ameliorate the association between deployment stressors and PTSD. ${ }^{39}$ Our findings suggest that, unfortunately, female Veterans believe that they are less likely to be supported in coping with war-zone stressors by their military peers.

A substantial proportion of women were exposed to some level of combat $(73.4 \%)$ and combat aftermath (73\%), demonstrating that, while the theoretical debate of whether or not women should be integrated into all combat roles continues, ${ }^{40,41}$ most female OEF/OIF troops are experiencing combat. However, given that women are currently prohibited from serving in many direct combat roles, men were significantly more likely than women to report these experiences. When stringently defined, more women reported aftermath of battle experiences $(15.4 \%)$ than combat experiences $(8.8 \%)$, as would be expected given the military positions open to women. These findings suggest that battle aftermath experiences should be included in combat exposure assessments when it is important to capture accurately the extent of stressful deployment events among women.

Our investigation is one of the first to examine genderdifferences in longer-term post-deployment adjustment. Female and male Veterans reported symptoms of probable PTSD in roughly equal numbers, just over $20 \%$ of both groups. Consistent with the general population ${ }^{22}$ and recent Veteran cohorts using administrative data from VA healthcare users, ${ }^{42}$ women appeared to be at higher risk for depression and men at higher risk for clinically significant alcohol use. These findings may indicate that these disorders are gender-linked conditions for the expression of post-deployment distress, possibly resulting from gender differences in biology, cognition or societal norms governing expressions of sadness and substance use.

Notably, the associations of both harassment and combat stress with probable PTSD were similar across genders. This adds to the evidence suggesting gender differences in PTSD observed in other populations are not found among OEF/OIF Veterans. Perhaps the increasing similarity in women's and men's military experiences (e.g., training, preparation for deployment, deployment experiences) may override pre-existing differences in women's and men's vulnerability when exposed to extreme stressors. Despite evidence from the general population that the prevalence of PTSD is twice as high in women than in men, ${ }^{43}$ data from specific traumatized populations suggests that the genderspecific risk of PTSD varies significantly by trauma. For the first time, women experiencing combat trauma exist in 
sufficient numbers to investigate these important questions empirically. Accordingly, this cohort of women Veterans represents a new and important population for understanding the gender-specific phenomenology of PTSD, which provides evidence that the gender-specific risk of PTSD is not absolute.

This investigation has limitations worth noting. Our results are subject to limitations inherent in self-report and cross-sectional data. Further, participants were selected using random sampling from the full population of separated OEF/OIF Veterans; however, they were not stratified on demographic or military variables, and are not necessarily fully representative of the larger population. Additionally, while our response rate is comparable to other large-scale, methodologically strong OEF/OIF Veteran surveys, ${ }^{28,44}$ the response rate of $48.6 \%$ may limit generalizability. Concerns about representativeness are somewhat alleviated by the knowledge that responders and nonresponders were similar in terms of gender, race, rank, military branch and component. While a larger age difference existed, the application of weights to account for nonresponse provides more confidence in the generalizability of the results with respect to these characteristics.

Despite limitations, these results are critical to quantifying gender-specific war-zone experiences and highlighting the changing role of women in today's military. Our results document important gender differences in deployment stressors, including women's increased risk of experiencing sexual harassment, general harassment and poorer unit support, as well as in post-deployment adjustment, including women's increased risk of depression. While these differences should not be ignored, our results also provide evidence that the experiences of male and female service members in today's military are more similar than ever before. Perhaps most importantly, our results indicate that despite female service members' increased risk of interpersonal stressors, and in contrast to some expectations of the impact of war on women, the post-deployment adjustment of our nation's growing population of female Veterans seems comparable to that of our nation's male Veterans.

Acknowledgements: The authors wish to thank Paula P. Schnurr, Ph.D. for her helpful comments on an earlier version of this manuscript.

This research was supported by the National Center for PTSD, Office of Mental Health Services, Department of Veterans Affairs. The views expressed in this article are those of the authors and do not necessarily reflect the position or policy of the Department of Veterans Affairs or the United States government. The funding agency was not involved in the design and conduct of the study; collection, management, analysis, and interpretation of the data; or the preparation, review, or approval of the manuscript.

Portions of this material were previously presented by the corresponding author at the November, 2010 Annual Meeting of the International Society of Traumatic Stress Studies, Montreal, Canada.
Conflicts of Interest: The authors declare that they do not have a conflict of interest.

Corresponding Author: Amy E. Street, $\mathrm{PhD}$; , National Center for PTSD, VA Boston Healthcare System, 150 South Huntington Avenue (116B-3), Boston, MA 02130, USA (e-mail: amy.street@va.gov).

\section{REFERENCES}

1. Defense Manpower Data Center. Contingency Tracking System Profile of Service Members Ever Deployed (In Support of OEF/OIF from Sept. 2001-Oct. 2009), By Gender: Department of Defense; 2009.

2. Street AE, Vogt D, Dutra L. A new generation of women veterans: stressors faced by women deployed to Iraq and Afghanistan. Clin Psychol Rev. 2009;29(8):685-694.

3. Vogt D, Pless AP, King LA, King DW. Deployment stressors, gender, and mental health outcomes among Gulf War I veterans. J Trauma Stress. 2005; 18(3):272-284.

4. Rosen LN, Martin L. Psychological effects of sexual harassment, appraisal of harassment, and organizational culture among U.S. Army soldiers. Mil Med. 1998;163(2):63-67.

5. Street AE, Stafford J, Mahan CM, Hendricks A. Sexual harassment and assault experienced by reservists during military service: prevalence and health correlates. J Rehabil Res Dev. 2008;45(3):409-419.

6. Skinner KM, Kressin N, Frayne $\mathbf{S}$, et al. The prevalence of military sexual assault among female Veterans' administration outpatients. J Interpers Violence. 2000;15(3):291-310.

7. Kang H, Dalager N, Mahan C, Ishii E. The role of sexual assault on the risk of PTSD among Gulf War veterans. Ann Epidemiol. 2005;15(3):191195.

8. Kimerling R, Gima K, Smith MW, Street A, Frayne S. The Veterans Health Administration and military sexual trauma. Am J Public Health. 2007;97(12):2160-2166.

9. Rosen LN, Wright K, Marlowe D, Bartone P, Gifford RK. Gender differences in subjective distress attributable to anticipation of combat among U.S. Army soldiers deployed to the Persian Gulf during operation desert storm. Mil Med. 1999;164(11):753-757.

10. Vogt D, Vaughn R, Glickman ME, et al. Gender differences in combatrelated stressors and their association with postdeployment mental health in a nationally representative sample of U.S. OEF/OIF Veterans. J Abnorm Psychol. 2011;120(4):797-806.

11. Maguen S, Luxton DD, Skopp NA, Madden E. Gender differences in traumatic experiences and mental health in active duty soldiers redeployed from Iraq and Afghanistan. J Psychiatr Res. 2012;46:311316.

12. National Defense Authorization Act for Fiscal Year 1994, P.L. 103-160, SEC. 541-542, H.R. 2401-1131994.

13. Hoge CW, Clark JC, Castro CA. Commentary: Women in combat and the risk of post-traumatic stress disorder and depression. Int $\mathrm{J}$ Epidemiol. 2007;36(2):327-329.

14. Haskell SG, Gordon KS, Mattocks KM, et al. Gender difference in rates of depression, PTSD, pain, obesity, and military sexual trauma among Connecticut war Veterans of Iraq and Afghanistan. J. Women's Health. 2010;19(2):267-271.

15. Maguen S, Cohen B, Ren L, Bosch J, Kimerling R, Seal K. Gender differences in military sexual trauma and mental health diagnoses among Iraq and Afghanistan Veterans with posttraumatic stress disorder. Women's Health Issues. 2012;22-1:e61-e66.

16. Kimerling R, Street AE, Pavao J, et al. Military-related sexual trauma among veterans health administration patients returning from Afghanistan and Iraq. Am J Public Health. 2010;100(8):1409-1412.

17. Katz LS, Bloor LE, Cojucar G, Draper T. Women who served in Iraq seeking mental health services: Relationships between military sexual trauma, symptoms, and readjustment. Psychol Serv. 2007;4(4):239249.

18. Dutra L, Grubbs K, Greene C, et al. Women at war: Implications for mental health. J Trauma Dissociation. 2011;12(1):25-37. 
19. Luxton DD, Skopp NA, Maguen S. Gender differences in depression and PTSD symptoms following combat exposure. Depress Anxiety. 2010;27 (11): 1027-1033.

20. Skopp NA, Reger MA, Reger GM, Mishkind MC, Raskind M, Gahm GA. The role of intimate relationships, appraisals of military service, and gender on the development of posttraumatic stress symptoms following Iraq deployment. J Trauma Stress. 2011;24(3):277-286.

21. Mental health advisory team (MHAT) IV Operation Iraqi Freedom 05-07 [news and media link]. 2006; http://www.armymedicine.army.mil/ reports/mhat/mhat_iv/MHAT_IV_Report_17NOV06.pdf. Accessed December 14, 2012.

22. National Comorbidity Survey Replication. Lifetime prevalence of DSM_IV/ WMH-CIDI disorders by sex and cohort. In: NCS-R appendix table, ed. http: / /www.hcp.med.harvard.edu/ncs/ftpdir/NCSR_Lifetime_ Prevalence_Estimates.pdf2007. Accessed December 14, 2012.

23. Dillman DA. Mail and Internet Surveys: The Tailored Design, Second Edition-2007 Update. Hoboken: John Wiley; 2007.

24. King DW, King LA, Vogt DS. Manual for the Deployment Risk and Resilience Inventory (DRRI): a collection of measures for studying deployment-related experiences of military veterans. Boston, MA: National Center for PTSD; 2003.

25. King LA, King DW, Vogt D, Knight J, Samper RE. Deployment risk and resilience inventory: A collection of measures for studying deploymentrelated experiences of military personnel and Veterans. Mil Psychol. 2006; 18(2):89-120.

26. Vogt D, Proctor SP, King DW, King LA, Vasterling JJ. Validation of scales from the Deployment Risk and Resilence Inventory in a sample of Iraq War Veterans. Assessment. 2008;15(4):391-403.

27. Weathers FW, Huska JA, Keane TM. PCL-M for DSM-IV. Boston: National Center for PTSD-Behavioral Science Division. 1991.

28. Tanielian T, Jaycox LH, eds. Invisible wounds of war: Psychological and cognitive injuries, their consequences, and services to assist recovery. Santa Monica, CA: The RAND Corporation; 2008. RAND Corporation monograph series.

29. Hotopf M, Hull L, Fear NT, et al. The health of UK military personnel who deployed to the 2003 Iraq war: a cohort study. Lancet. 2006;367 (9524):1731-1741.

30. Weathers FW, Litz BT, Herman DS, Huska JA, Keane TM. The PTSD Checklist (PCL): Reliability, validity, and diagnostic utility. Paper presented at: 9th annual meeting of the International Society for Traumatic Stress Studies 1993; San Antonio, Texas.
31. Radloff LS. The CES-D scale: A self-report depression scale for research in the general population. Appl Psychol Meas. 1977;1:385-401.

32. Andresen EM, Malmgren JA, Carter WB, Patrick DL. Screening for depression in well older adults: evalutation of a short form of the CES-D (Center for Epidemiologic Studies Depression Scale). Am J Prev Med. 1994;10(2):77-84.

33. Lovibond PF, Lovibond SH. The structure of negative emotional states: Comparison of the Depression Anxiety Stress Scales (DASS) with the Beck Depression and Anxiety Inventories. Behav Res Therapy. 1995;33:335-343.

34. Lovibond SH, Lovibond PF. Manual for the depression anxiety stress scales. Sydney: The Psychology Foundation of Australia; 1995.

35. Ewing JA. Detecting alcoholism: The CAGE questionnaire. JAMA. 1984;252:1905-1907.

36. Buchsbaum DG, Buchanan RG, Centor RM, Schnoll SH, Lawton MJ. Screening for alcohol abuse using CAGE scores and likelihood ratios. Ann Intern Med. 1991;115(10):774-777.

37. Groves R, Dillman D, Eltinge J, Little R. Survey Nonresponse. New York: Wiley; 2002.

38. Greenland S. Introduction to Regression Modeling. In: Rothman KJ, Greenland S, Lash TL, eds. Modern Epidemiology. 3rd ed. Philadelphia: Lippincott, Williams, \& Wilkins; 2008:418-458.

39. Brailey K, Vasterling JJ, Proctor SP, Constans JI, Friedman MJ. PTSD symptoms, life events, and unit cohesion in U.S. soldiers: baseline findings from the neurocognition deployment health study. J Trauma Stress. 2007;20(4):495-503.

40. Clemmitt M. Women in the military. Congressional Quarterly Researcher. 2009;19(40):957-980.

41. Martin R. Panel to recommend allowing women in combat. NPR. January, 2011. http://www.npr.org/2011/01/13/132882277/Panel-ToRecommend-Allowing-Women-In-Combat. Accessed December 14, 2012.

42. Maguen S, Ren L, Bosch JO, Marmar CR, Seal KH. Gender differences in mental health diagnoses among Iraq and Afghanistan Veterans enrolled in Veterans Affairs health care. Am J Public Health. 2010;100 (12):2450-2456.

43. Tolin DF, Foa EB. Sex differences in trauma and posttraumatic stress disorder: A quantitative review of 25 years of research. Psychol Bull. 2006;132(6):959-992.

44. Smith B, Smith TC, Gray GC, Ryan MA. When epidemiology meets the Internet: Web-based surveys in the Millennium Cohort Study. Am J Epidemiol. 2007;166(11):1345-1354. 